\title{
MEDICAL REHABILITATION MANAGEMENT OF CARPAL TUNNEL SYNDROME
}

\author{
Imam Subadi ${ }^{1}$, Hanik B. Hidayati ${ }^{2}$, Fidiana ${ }^{2}$, Nur Sulastri ${ }^{3}$ \\ ${ }^{l}$ Department of Physical Medicine and Rehabilitation, Faculty of Medicine, Airlangga University, Surabaya, Indonesia \\ ${ }^{2}$ Department of Neurology, Faculty of Medicine, Airlangga University, Surabaya, Indonesia \\ ${ }^{3}$ Department of Physical Medicine and Rehabilitation of Airlangga University Hospital, Surabaya, Indonesia \\ Correspondence : hanikhidayati@fk.unair.ac.id
}

\begin{abstract}
Carpal tunnel syndrome (CTS), the most common entrapment neuropathy in the upper extrimity, is a clinical syndrome characterized by a tingling sensation, numbness, pain, or weakness in the hand and wrist radiating up to the arm. This condition is a major cause of absenteeism, reduced productivity, and financial loss among various neuropathy due to median nerve compression. This paper, medical rehabilitation of CTS is viewed. Medical rehabilitation of CTS aimed to reduce pain, reduce clamping of the carpal tunnel, sensory and motor reeducation so that hand function improves and can perform activities of daily living. Treatment options can be given includes exercise therapy, ultrasound diathermy, low level laser therapy (LLLT), and shock wave therapy (SWT).
\end{abstract}

Keyword : Carpal tunnel syndrome, exercise, ultrasound diathermy, laser therapy, shock wave therapy

\section{PENDAHULUAN}

Sindroma terowongan karpal atau carpal tunnel syndrome (CTS) adalah kondisi yang membuat tangan mengalami sensasi kesemutan, mati rasa, nyeri, atau kelemahan. Sindroma ini disebabkan penjepitan saraf medianus pada terowongan karpal (1). Prevalensi CTS dilaporkan sekitar antara $7 \%$ sampai $19 \%$ dari populasi (2). Prevalensi tertinggi $61 \%$ terjadi pada pekerja industri terutama yang menggunakan alat grenda, sedangkan $1 \%$ yang jarang menggunakan tangan secara berulang. Faktor risiko terjadinya CTS adalah penggunaan tangan dan pergelangan tangan yang berulang-ulang, postur yang jelek, angkat berat, dan vibrasi, juga obesitas, jenis kelamin wanita, usia lanjut dan merokok (3).

Pada studi kualitatif deskriptif, penderita dengan CTS dilaporkan bahwa gejala sensorik paling dominan. Dilaporkan penderita mengalami gangguan manipulasi obyek kecil dan mengangkat beban. Penderita dengan CTS juga sering dijumpai kelemahan otot. Kelemahan genggaman dan pinch menyebabkan gangguan fungsi tangan dan secara keseluruhan mengganggu aktifitas hidup sehari-hari (4). CTS merupakan penyebab utama tidak masuk kerja, menurunkan produktifitas, dan hilangnya finansial di antara berbagai neuropati karena penjepitan saraf (3). Nyeri neuropati merupakan nyeri kronik yang melemahkan (5) dan berdampak pada gangguan pada banyak aspek kehidupan pasien seperti pekerjaan, kesehatan, hubungan sosial, tidur, hobi, mood maupun kognitif, bahkan kecelakaan lalu lintas di kota dengan penduduk yang padat (6). Di Amerika Serikat pada tahun $1995,400.000-500.000$ penderita CTS memerlukan dekompresi dan memerlukan biaya sekitar 2 milyar dollar (7).

Tatalaksana CTS diberikan berdasarkan beratnya penyakit. Pada kasus ringan dan sedang, direkomendasikan terapi konservatif (8). Penderita CTS berat atau kerusakan saraf pada pemeriksaan elektrodiagnostik dilakukan pembedahan dekompresi. Terapi konservatif meliputi splinting, kortikosteroid, terapi latihan, terapi panas, yoga (9), terapi laser, akupunktur (10), terapi listrik, terapi gelombang suara, terapi medan magnet (11) dan terapi bekam (12). Obat yang paling sering digunakan adalah prednisolone, methylprednisolone, dexamethasone sodium phosphate, triamcinolone acetonide, methylprednisolone acetate, lidocaine, dan diclofenac diethylammonium (13). Mekanisme kerja modalitas terapi tersebut di atas meliputi mengurangi nyeri, merangsang proses restorasi, meningkatkan luas gerak sendi, mengaktifkan mekanisme imun dan meningkatkan performa biomolekuler (11).

Nyeri merupakan alasan terbanyak pasien mencari pertolongan medis (14-16). Rehabilitasi medik penderita CTS bertujuan mengurangi nyeri,

mengurangi penjepitan pada terowongan karpal, reedukasi sensorik dan motorik sehingga fungsi tangan meningkat dan dapat melakukan aktifitas hidup sehari-hari. Pada CTS, pembengkakan saraf medianus telah diidentifikasi secara intra-operatif, dengan ultrasound imaging, dan dengan Magnetic Resonance Imaging (MRI)..

\section{Article History}

Received: August 23, 2021; August 30, 2021; Published: : September 1, 2021

Cite As:

Subadi I, Hidayati HB, Fidiana F, Sulastri N. Medical rehabilitation management of carpal tunnel syndrome. Journal of Pain, Vertigo and Headache; 2021.2:34-37 
Bila keadaan penjepitan terjadi pada jangka panjang maka edema intraneural potensial terjadi fibrosis yang irreversible. Pengurangan edema merupakan target terapi CTS (17).

\section{GRADASI CTS}

Secara umum hasil pemeriksaan elektrofisiologis pada CTS berupa: menurunnya kecepatan hantar saraf (KHS) pada saat melintasi terowongan karpal, memanjangnya latensi distal motorik (LDM), menurunnya amplitudo sensory nerve action potensial (SNAP), dan menurunnya amplitudo compound muscle action potential (CMAP) saraf medianus, serta ditemukannya aktifitas spontan berupa fibrilasi pada otot abductor pollicis brevis (18).

Berdasarkan pemeriksaan elektrofisiologis, derajat CTS dapat ditentukan ringan, sedang dan berat. Derajat ringan bila pada pemeriksaan elektrodiagnostik ditemukan abnormalitas sensorik saraf medianus; sedang ditemukan pemanjangan LDM terhadap abductor pollicis brevis dengan CMAP normal; sedangkan berat bila ditemukan menurunnya CMAP atau EMG abnormal pada otot thenar (19).

\section{REHABILITASI MEDIK PADA CTS}

\section{Terapi Latihan}

Terapi latihan direkomendasikan untuk CTS derajat ringan dan sedang atau menunggu operasi. Latihan menurunkan tekanan intrakarpal dan inflamasi, juga memperbaiki arus balik vena dengan cara menurunkan edema dan adesi (20).

Latihan yang paling sering dilakukan untuk CTS adalah median nerve glide mobilization dan tendon glide (Gambar 1 dan 2) (21). Efek biomekaniknya adalah memperbaiki mobilisasi saraf dan menurunkan edema dan adesi pada terowongan karpal. Mempertahankan posisi netral pergelangan tangan memperbaiki sirkulasi darah sehingga menurunkan edema (17). Latihan yang dianjurkan satu sampai lima kali per hari dengan 5 - 10 repetisi (20).
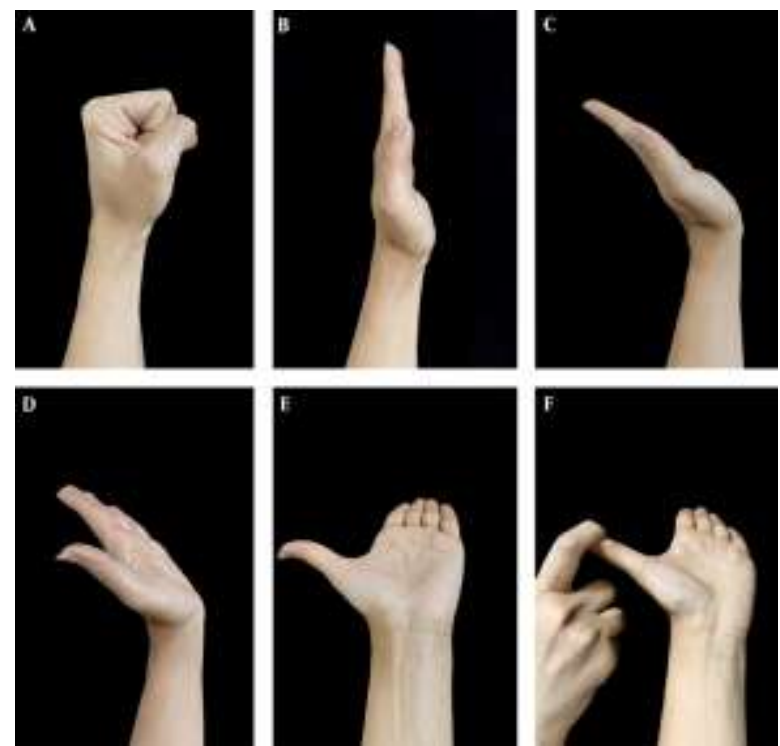

Gambar 1. Latihan nerve gliding. A. Pergelangan tangan posisi netral, jari-jari dan ibu jari posisi fleksi; B. Pergelangan tangan posisi netral, jari-jari dan ibu jari posisi ekstensi; C. Pergelangan

tangan dan jari-jari posisi ekstensi, ibu jari posisi netral; D.

Pergelangan tangan, jari-jari dan ibu jari ekstensi; E. Seperti D namun lengan bawah supinasi; F. Seperti E dengan peregangan ibu jari (20).
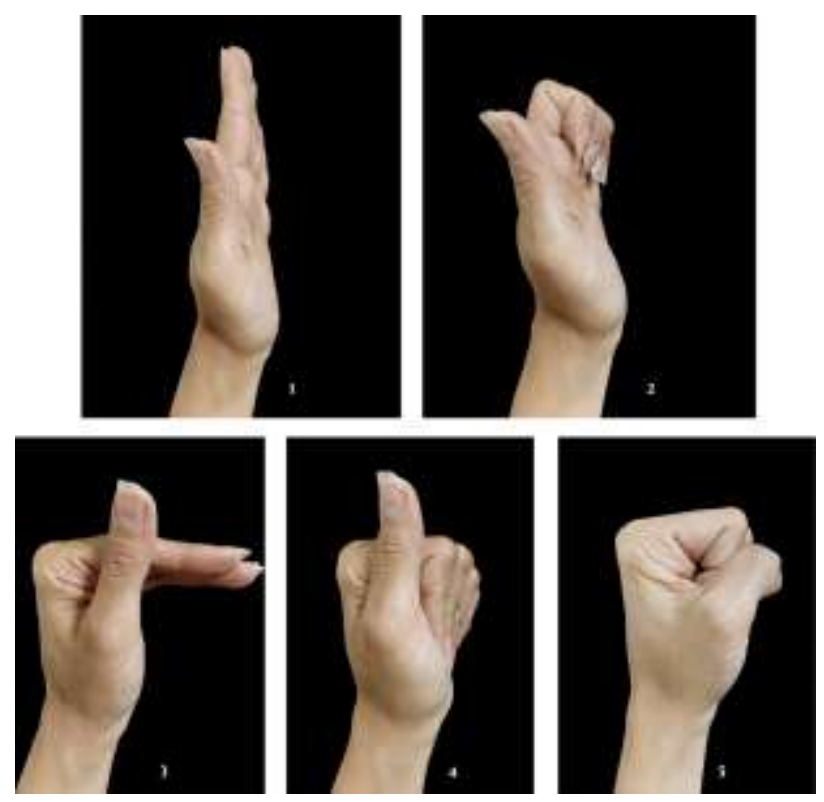

Gambar 2. Latihan tendon gliding. (1) straight; (2) straight fist; (3) table top; (4) fist; (5) hook (20).

\section{Ultrasound diathermy}

Mekanisme terapi ultrasound meliputi efek termal dan non termal. Efek termal terjadi saat gelombang suara penetrasi ke jaringan dan menyebabkan vibrasi molekul dan menghasilkan panas. Efek non termal meliputi kavitasi, massage yang dapat memicu efek anti-inflamasi dan rangsangan jaringan (22). Beberapa penelitian terapi ultrasound menunjukkan efek positif pada CTS (23), terutama ditambah ortesa pergelangan tangan (22), namun menurut Cochrane review kualitas terapi ultrasound dibandingkan placebo jelek pada jangka pendek dan jangka panjang (20). Latihan neural mobilization saraf medianus lebih efektif dibandingkan terapi ultrasound (24).

\section{Low level laser therapy (LLLT)}

LLLT merupakan terapi alternatif non pembedahan. Secara umum, LLLT mempunyai efek meningkatkan produksi endorphin, serotonin dan beberapa mediator yang menurunkan inflamasi (25). Beberapa studi menunjukkan bahwa LLLT meningkatkan hand grip, visual analogue scale (VAS), dan SNAP setelah 3 bulan terapi (26). Bekhet dkk

juga menunjukkan LLLT superior terhadap placebo dalam hal kekuatan otot tangan (27). Pada studi perbandingan antara high intensity laser therapy (HILT) dengan LLLT didapatkan HILT lebih superior dibandingkan LLLT meskipun pada combined sensory index (CSI) saja (28). Menurut Cochrane review, studi LLLT menunjukkan efek tidak berbeda dibandingkan placebo maupun ultrasound terapi (29). Studi meta-analisis menunjukkan bahwa LLLT tidak lebih superior dibandingkan sham laser (30).

\section{Shockwave therapy (SWT)}

SWT merupakan tindakan non-invasif dan secara evidencebased digunakan untuk terapi CTS. SWT merupakan gelombang kejut dan mempunyai frekwensi rendah $(2-20$ $\mathrm{Hz}$ ) dengan tekanan $1-5$ bar. Gelombang kejut tersebut diarahkan ke ligamen carpi transversalis (11). SWT memicu ekspresi adenosine triphosphate (ATP) untuk aktifasi jalur signal sel, meningkatkan permeabilitas membran sel, mobilisasi kalsium, angiogenesis, efek anti-inflamasi, merangsang makrofag dari M1 menjadi M2 sehingga 
merangsang mediator IL-4, IL-5, IL-9 dan IL-13. Makrofag M2 juga merangsang proliferasi sel dan perbaikan sel (31).

Pada studi systematic review dan meta-analisis menunjukkan bahwa SWT memperbaiki gejala, fungsi, dan parameter elektrofisiologi penderita CTS (32). SWT direkomendasikan sebagai terapi CTS dengan derajat ringan, sedang maupun berat kecuali terdapat gangguan motorik (33). Gesslbauer dkk. menggunakan extracorporeal shock wave therapy (ESWT) untuk CTS dan mendapatkan penurunan VAS pada minggu ketiga dan keduabelas, dan perbaikan hand grip pada minggu keduabelas (34). Wu dkk. menggunakan radial shock wave therapy (RSWT) untuk CTS dan menunjukkan perbaikan VAS, cross-sectional area (CSA) saraf medianus dan menurunkan disabilitas (35).

\section{RINGKASAN}

Rehabilitasi medik penderita CTS penting dilakukan sejak awal. Latihan efektif menurunkan gejala CTS. Meskipun ultrasound maupun laser dapat digunakan sebagai terapi alternatif CTS namun yang paling efektif adalah SWT.

\section{REFERENSI}

1. Kadarusman TA, Hidayati HB, Sugianto P. Analgesic Drug Use for Carpal Tunnel Syndrome. JUXTA J Ilm Mhs Kedokt Univ Airlangga; 2019. 10(1):1.

2. Cazares-Manríquez MA, Wilson CC, Vardasca R, García-Alcaraz JL, Olguín-Tiznado JE, López-Barreras JA, et al. A review of carpal tunnel syndrome and its association with age, body mass index, cardiovascular risk factors, hand dominance, and sex. Appl Sci; 2020. 10(10).

DOI: https://doi.org/10.3390/app10103488

3. Feng B, Chen K, Zhu X, Ip WY, Andersen LL, Page P, et al. Prevalence and risk factors of self-reported wrist and hand symptoms and clinically confirmed carpal tunnel syndrome among office workers in China: A cross-sectional study. BMC Public Health; 2021. 21(1). Avalaible from:

https://bmcpublichealth.biomedcentral.com/articles/10. 1186/s12889-020-10137-1

4. Nazari G, Shah N, MacDermid JC, Woodhouse L. The Impact of sensory, motor and pain impairments on patient- reported and performance based function in carpal tunnel syndrome. Open Orthop J; 2017. 11(1):1258-67. DOI: 10.2174/1874325001711011258

5. Hidayati HB, MacHfoed MH, Kuntoro, Subadi I, Khaerunnisa S, Widjiati. Increase in the glutamate transporter 1 and time withdrawal latency following wet cupping therapy in chronic constriction injury in rats. Anaesthesia, Pain Intensive Care; 2021. 25(1):50-6. DOI: 10.35975/apic.v25i1.1441

6. Hidayati HB, Sugianto P, Khotib J, Ardianto C, Kuntoro K, Machfoed MH. Pengukuran tingkah laku pada model nyeri neuropatik perifer: Tikus dengan cci (chronic constriction injury). Maj Kedokt Neurosains Perhimpun Dr Spes Saraf Indonesia; 2018. 35(3):20914. DOI: 10.35975/apic.v25i1.1441

7. Ibrahim I, Khan W, Goddard N, Smitham P. Carpal tunnel syndrome: A review of the recent literature.
Open Orthop J; 2012. Page 69-76.

DOI: $10.2174 / 1874325001206010069$

8. Hernández-Secorún M, Montaña-Cortés R, HidalgoGarcía C, Rodríguez-Sanz J, Corral-De-toro J, MontiBallano S, et al. Effectiveness of conservative treatment according to severity and systemic disease in carpal tunnel syndrome: A systematic review. Int $\mathrm{J}$ Environ Res Public Health; 2021. 18(5):1-34.

DOI: $10.3390 /$ ijerph18052365.

9. Wipperman J, Goerl K. Carpal tunnel syndrome: Diagnosis and management. Am Fam Physician; 2016. 94(12):993-9. Avalaible from: https://www.aafp.org/afp/2016/1215/p993.html

10. Carlson H, Colbert A, Frydl J, Arnall E, Elliott M, Carlson N. Current options for nonsurgical management of carpal tunnel syndrome. Int J Clin Rheumtol; 2010. 5(1):129-42. DOI: 10.2217/IJR.09.63

11. Zaralieva A, Georgiev GP, Karabinov V, Iliev A, Aleksiev A. Physical therapy and rehabilitation approaches in patients with carpal tunnel syndrome. Cureus; 2020. DOI: 10.7759/cureus.7171

12. Hidayati HB, Machfoed MH, Santoso B, Utomo B. Cupping as a pain alternative therapy. Tinj Pustaka Neurona; 2019. 36(2):148. Avalaible from : https://www.neurona.web.id/paper-detail.do?id=1097

13. Jiménez del Barrio S, Bueno Gracia E, Hidalgo García C, Estébanez de Miguel E, Tricás Moreno JM, Rodríguez Marco S, et al. Tratamiento conservador en pacientes con síndrome del túnel carpiano con intensidad leve o moderada. Revisión sistemática. Neurología [Internet]. 2018 Nov;33(9):590-601.

Available from:

https://linkinghub.elsevier.com/retrieve/pii/S021348531 6300949

14. Hidayati HB. Ultrasound and management strategies in chronic pain. Anaesth Pain Intensive Care; 2020. 24(6):579-81.

DOI: https://doi.org/10.35975/apic.v24i6.1393

15. Hidayati HB, Kustriyani A. Paracetamol, migraine, and medication overuse headache (MOH). JPHV (Journal Pain, Vertigo Headache); 2020. 1(2):42-7.

DOI: https://doi.org/10.21776/ub.jphv.2020.001.02.5

16. Hidayati HB. Carbamazepine as a pain treatment of trigeminal neuralgia. JPHV (Journal Pain, Vertigo Headache); 2020. 1(2):37-41.

DOI: https://doi.org/10.21776/ub.jphv.2020.001.02.4

17. Schmid AB, Elliott JM, Strudwick MW, Little M, Coppieters MW. Effect of splinting and exercise on intraneural edema of the median nerve in carpal tunnel syndrome-an MRI study to reveal therapeutic mechanisms. J Orthop Res; 2012. 30(8):1343-50. DOI: 10.1002/jor.22064

18. Hamid DH, Hakim M, Octaviana F, Yanuar A. Grading sindrom terowongan karpal berdasarkan pemeriksaan lumbrikalinterosei. Neurona Maj Kedokt Neuro Sains. 
2011; Vol 28 No.(4). Avalaible from: https://www.neurona.web.id/paper-detail.do?id=778

19. Sonoo M, Menkes DL, Bland JDP, Burke D. Nerve conduction studies and EMG in carpal tunnel syndrome: Do they add value? Clin Neurophysiol Pract; 2018. 3:78-88. DOI: 10.1016/j.cnp.2018.02.005

20. Nazarieh M, Hakakzadeh A, Ghannadi S, Maleklou F, Tavakol Z, Alizadeh Z. Non-surgical management and post-surgical rehabilitation of carpal tunnel syndrome: An algorithmic approach and practical guideline. Asian J Sports Med; 2020. 11(3):1-13.

DOI: 10.5812 asjsm.102631

21. Ballestero-Pérez R, Plaza-Manzano G, Urraca-Gesto A, Romo-Romo F, Atín-Arratibel M de los Á, PecosMartín D, et al. Effectiveness of nerve gliding exercises on carpal tunnel syndrome: A systematic review. J Manipulative Physiol Ther; 2017. 40(1):50-9.

DOI: 10.1016/j.jmpt.2016.10.004

22. Chang YW, Hsieh SF, Horng YS, Chen HL, Lee KC, Horng YS. Comparative effectiveness of ultrasound and paraffin therapy in patients with carpal tunnel syndrome: A randomized trial. BMC Musculoskelet Disord; 2014. 15(1). DOI: 10.1186/1471-2474-15-399

23. Siddiquee N, Mishu FA, Rahman S, Zaman AKA. Evaluation of ultrasound therapeutic effect on patients with carpal tunnel syndrome attending in a tertiary care hospital of Bangladesh. BIRDEM Med J; 2019. 9(1):70-3.

DOI: https://doi.org/10.3329/birdem.v9i1.39728

24. Alam M, Khan M, Ahmed SI, Ali SS. Effectiveness of neural mobilization and ultrasound therapy on pain severity in carpal tunnel syndrome. Biomed Res Ther; 2018. 5(4):2187-93. Avalaible from: http://www.bmrat.org/index.php/BMRAT/article/view/ 432

25. Martins RS, Siqueira MG. Conservative therapeutic management of carpal tunnel syndrome. Arq Neuropsiquiatr; 2017. 75(11):819-24.

DOI: $10.1590 / 0004-282 X 20170152$

26. Li ZJ, Wang Y, Zhang HF, Ma XL, Tian P, Huang Y. Effectiveness of low-level laser on carpal tunnel syndrome: A meta-analysis of previously reported randomized trials. Med (United States); 2016. 95(31). DOI: 10.1097/MD.0000000000004424

27. Bekhet AH, Ragab B, Abushouk AI, Elgebaly A, Ali OI. Efficacy of low-level laser therapy in carpal tunnel syndrome management: A systematic review and meta- analysis. Lasers Med Sci; 2017. 32(6):1439-48.

DOI: $10.1007 / \mathrm{s} 10103-017-2234-6$

28. Sudiyono N, Handoyo R. Comparison of high-intensity and low-level laser therapy effecton combined sensory index, sensory conduction velocity and distal motoric latency: A study in moderate carpal tunnel syndrome patients. J thee Med Sci (Berkala Ilmu Kedokteran); 2020. 52(4)

DOI: https://doi.org/10.19106/JMedSci005204202006

29. Rankin IA, Sargeant H, Rehman H, Gurusamy KS. Low-level laser therapy for carpal tunnel syndrome. Cochrane Database Syst Rev; 2017. 2017(8). DOI: 10.1002/14651858.CD012765

30. Cheung WKW, Wu IXY, Sit RWS, Ho RST, Wong CHL, Wong SYS, et al. Low-level laser therapy for carpal tunnel syndrome: systematic review and network meta-analysis. Physiother (United Kingdom); 2020. 106:24-35. DOI: 10.1016/j.physio.2019.06.005

31. Simplicio CL, Purita J, Murrell W, Santos GS, dos Santos RG, Lana JFSD. Extracorporeal shock wave therapy mechanisms in musculoskeletal regenerative medicine. J Clin Orthop Trauma; 2020. 11:S309-18. DOI: $10.1016 /$ j.jcot.2020.02.004

32. Kim JC, Jung SH, Lee SU, Lee SY. Effect of extracorporeal shockwave therapy on carpal tunnel syndrome: A systematic review and meta-analysis of randomized controlled trials. Med (United States); 2019. 98(33). DOI: 10.1097/MD.0000000000016870

33. Rashad UM, Kishk NA, Mansour WT, Nawito AM, Khalil AS, Helmy $\mathrm{H}$, et al. Effect of extracorporeal shock wave therapy on different severities of carpal tunnel syndrome. Egypt J Neurol Psychiatry Neurosurg; 2020. 56(1). Avalaible from: https://ejnpn.springeropen.com/articles/10.1186/s41983 -020-00181-4

34. Gesslbauer C, Mickel M, Schuhfried O, Huber D, Keilani M, Crevenna R. Effectiveness of focused extracorporeal shock wave therapy in the treatment of carpal tunnel syndrome: A randomized, placebocontrolled pilot study. Wien Klin Wochenschr; 2021. 133(11-12):568-77. DOI: 10.1007/s00508-020-017859

35. Wu YT, Ke MJ, Chou YC, Chang CY, Lin CY, Li TY, et al. Effect of radial shock wave therapy for carpal tunnel syndrome: A prospective randomized, doubleblind, placebo-controlled trial. J Orthop Res; 2016. 34(6):977-84. DOI: 10.1002/jor.23113 